This item was submitted to Loughborough's Research Repository by the author.

Items in Figshare are protected by copyright, with all rights reserved, unless otherwise indicated.

\title{
Meeting the expectation of industry: an integrated approach for the teaching of mechanics and electronics to design students
}

PLEASE CITE THE PUBLISHED VERSION

http://dx.doi.org/10.1080/03043797.2014.1001813

\section{PUBLISHER}

Taylor and Francis Ltd. (@ 2015 SEFI)

VERSION

AM (Accepted Manuscript)

\section{PUBLISHER STATEMENT}

This work is made available according to the conditions of the Creative Commons Attribution-NonCommercialNoDerivatives 4.0 International (CC BY-NC-ND 4.0) licence. Full details of this licence are available at: https://creativecommons.org/licenses/by-nc-nd/4.0/

\section{LICENCE}

CC BY-NC-ND 4.0

\section{REPOSITORY RECORD}

Bingham, Guy A., Darren J. Southee, and Tom Page. 2019. "Meeting the Expectation of Industry: An Integrated Approach for the Teaching of Mechanics and Electronics to Design Students". figshare. https://hdl.handle.net/2134/18683. 


\section{Meeting the expectation of industry: An integrated approach for the teaching of Mechanics and Electronics to design students}

Guy A Bingham*, Darren J Southee and Tom Page

Loughborough Design School, Loughborough University, Loughborough, Leicestershire, LE1 13TU, UK

Corresponding author*: Dr. Guy Bingham: g.a.bingham@lboro.ac.uk

Telephone number: $+44(0) 1509222653$

\section{Dr. Guy A Bingham}

Guy Bingham is a Senior lecturer and Programme Director for the postgraduate Industrial Design programme at the Loughborough University Design School, specialising in the delivery of Engineering, Mechanics and Design practice. Guy is a member of the Institute of Engineering Design and serves on their committee for Education and Training. Guy is a member of two research groups at Loughborough University: Additive Manufacturing Research Group and the Design Practice Research Group. His research interests include Additive Manufacturing, Computer Aided Design and Digital Design practice.

\section{Dr. Darren J Southee}

Darren Southee is currently Programme Director for the BSc Product Design \& Technology programme in the Design School at Loughborough University. His 20 year academic career has included roles for Bournemouth University, Bradford University (United Arab Emirates), the University of Lincoln (Hull Campus), Brunel University and Loughborough University. He was Deputy Head of Design, Course Director for Industrial Design \& Technology and a member of the Cleaner Electronics Research Group at Brunel. He is a member of the Design Practice Research Group.

\section{Dr. Tom Page}

Tom Page is a Senior lecturer in Electronic Product Design in the Loughborough Design School. His research interests are in the areas of Engineering Design, Value Management, Technology Education and Electronic Product Design. His work has been widely published in journal papers, book contributions, refereed proceedings, refereed conference papers and technical papers. 


\title{
Meeting the expectation of industry: An integrated approach for the teaching of Mechanics and Electronics to design students
}

\begin{abstract}
This paper examines the traditional engineering-based provision delivered to Product Design and Technology (BSc) undergraduates at the Loughborough Design School and questions its relevancy against the increasing expectations of industry. The paper reviews final year design projects to understand the level of transference of engineeringbased knowledge into design practice and highlights areas of opportunity for improved teaching and learning. The paper discusses the development and implementation of an integrated approach to the teaching of Mechanics and Electronics to formalise and reinforce the key learning process of transference within the design context. The paper concludes with observations from the delivery of this integrated teaching and offers insights from student and academic perspectives for the further improvement of engineering-based teaching and learning.
\end{abstract}

Keywords: Design Education; Product Design; Engineering Design; Industrial Design; Mechanics; Electronics

Word count: 8,200 


\subsection{Introduction}

In recent years, industry's expectations of design and engineering graduates have changed (de Vere et al 2010). Advances in new technology, the economic climate and the increasing consumer requirement for more technologically advanced products are just a few of the factors driving their growing expectation (Southee 2005). Increasingly, employers of design and engineering graduates (for the creation of modern products) expect an immediate and valuable contribution to their profitability, and require higher levels of product maturity at launch, where previously this was only achieved and/or expected after several years of exposure to the market (Green and Smrcek 2006). The increasing expectation means design and engineering graduates must be practised, creative and solution-focused with a strong technical knowledge-base, understanding of human-centred design and an ability to work in multidisciplinary contexts (Grasso and Martinelli 2007). These desirable qualities are an interesting mix of attributes associated with graduates from a range of academic subjects, including: Industrial design, Engineering and Electrical Engineering, resulting in an education shift towards Product Design as an academic subject. Product Design is the academic solution to the changing industrial requirements and aims to create graduates with the expected attributes through a combined curriculum. The subject can be described as 'a generic term for the creation of an object that originates from design ideas - in the form of drawings, sketches, prototypes or models - through a process of design that can extend into the objects production, logistics, and marketing' (Slack 2006, p. 6).

Product design as an academic subject has resulted in two distinct educational approaches, an engineering emphasis and a design emphasis. Product Design Engineering (PDE) delivered by engineering faculties or departments has been the engineering approach, while Product Design (PD) delivered by design faculties or schools has been the industrial design approach. Both approaches share common goals and expected attributes of their graduates; however, the two traditionally disparate fields differ in their pedagogy.

Traditional engineering pedagogy can be described as narrow and deep, with students often being taught isolated subjects using linear progression. Generally, they are provided the opportunity to practice the application of certain subjects through final-year projects, with the intention that they integrate the remaining subjects once they reach industry (Morris et al 2007). In contrast, the design pedagogy can be described as broad and deepening, using a holistic approach, students are exposed to an entire range of subjects from the beginning of their studies. As students progress through each level (year) of the programme, each subject is delivered in more comprehensive depth, building on the previous knowledge-base and promoting students to practice and develop their integrative skills. A further defining feature of design-based pedagogy is the continual adoption of Problem-Based Learning (PBL) (Savin-Baden and Major 2004). PBL provides a motivational and deep learning platform and has the advantage that design problems can be taken from real world examples, further engaging students with the subject matter by relation (Morris et al 2007). PBL also addresses a key issue in the cognitive sciences of transfer or transference which is defined as the ability to extend what has been learned in a particular context to other, new contexts and further reinforces their integrative skills (Bransford et al 1999).

A summary of the pedagogic differences between the two differing approaches is given in Error! Reference source not found., adapted from (Morris et al 2007).

\begin{tabular}{l|c|c|}
\hline Pedagogy & Engineering & Design \\
\hline Subject matter & Isolated, modular & Integrative, holistic \\
\hline Subject range & Narrow, deep & Broad, shallow \\
\hline Delivery & Lecture-based & Problem-based \\
\hline Creativity & Problem-solving & Problem defining \\
\hline Projects & Theoretical & Applied \\
\hline
\end{tabular}

Table 1: Pedagogic differences between engineering and design 
The pedagogic differences and interrelationship can be clearly visualised using a Venn diagram as demonstrated in Figure 1.

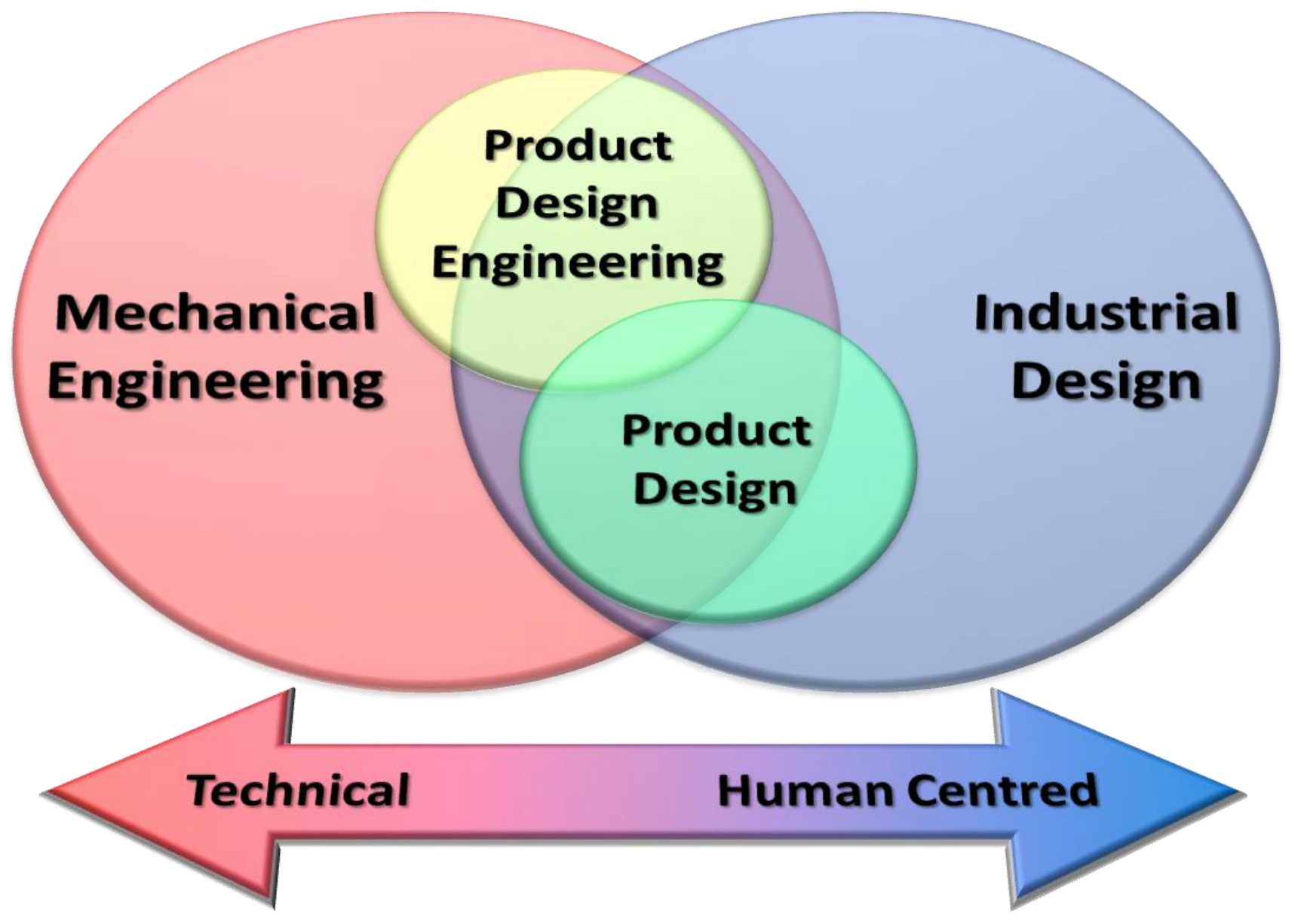

Figure 1: Interrelationships between engineering and design

Irrespective of the approach, a core subject for both pedagogic rationales of Product Design education is engineering design. The Accreditation Board for Engineering and Technology (ABET) defines engineering design as: 'The process of devising a system, component or process to meet desired needs. It is a decision-making process (often iterative), in which the basic sciences, mathematics and engineering sciences are applied to convert resources optimally to meet a stated objective. Among the fundamental elements of the design process are the establishment of objectives and criteria synthesis, construction, testing and evaluation' (ABET 2012). To date, there has been a significant amount of research addressing the design education of engineering students, including (Atman et al, 1999, Atman and Turns 2001, Atman et al 2005, Bursic and Atman 1997, Christiaans and Dorst, 1992, Cross 2001, Ennis and Gyeszly 1991, Kruger and Cross 2006, Pahl 1999, Radcliffe and Lee 1989, Stauffer and Ullman 1988). However, there is limited research addressing the engineering design education of design students. Useful texts on the subject include (Pugh 1991, Hyman 1998, Voland 1999, Dym and Little 2000, Cross 2000, Dominick et al 2001, Salti and Rothery 2002) but these focus mainly on mechanical design and lack human-centred consideration.

The action research presented here addresses this important issue and examines the teaching and learning of engineering design to design-based students at Loughborough University.

\subsection{Design education at Loughborough University}

Loughborough University offers both distinct approaches to Product Design education and they exist in complete isolation. Product Design Engineering BEng / MEng (Hons), delivered by the Wolfson School of Mechanical and Manufacturing engineering, is the engineering approach, while Product Design and Technology BSc (Hons), delivered by the Loughborough Design School, is the industrial design approach. This paper is concerned with the engineeringbased pedagogy of the Product Design and Technology BSc (Hons) programme delivered by the Design School. 
The Loughborough Design School offers four distinct undergraduate design-based programmes with a total student intake of approximately 175 students annually. The majority of the total student intake is registered on just two undergraduate degree programmes:

- Industrial Design and technology BA (Hons) - (IDT)

- Product Design and technology BSc (Hons) - (PDT)

The cohort sizes across both courses is approximately three-quarters IDT to one-quarter PDT and both programmes share the same core design principles (improved consumer products) and a substantial number of shared design modules. Both IDT and PDT run as a three year or four year sandwich programme with the majority ( $90 \%)$ of the students opting for the four year option with a year in industry as a Design Placement Study (DPS).

A common feature of all industrial and product design-based programmes delivered through design school environments is the use of Final Year Design Practice (FYDP) Projects. Normally a significant credit bearing module, the FYDP module is the culmination of all previous design education within the programme and provides the students with the opportunity to apply and practise their industrial or product design skills in an academic context. All industrial/product design education is driven to this aim and it is here where students' integrative skills and ability to implement transference is academically assessed.

\subsection{PDT and IDT differentiation}

The fundamental difference between the two programmes (PDT and IDT) at Loughborough University is the dedicated teaching of engineering-based subjects, specifically Mechanics and Electronics as distinct core modules to the PDT cohort. The purpose of this delivery is not the education of design engineers, but the education of product designers with broad and real capabilities who can respond to both the human-centred and technical challenges of contemporary (and future) product design requirements.

Utilising the broad and deepening educational approach, PDT students undertake dedicated modules for each subject (Mechanics and Electronics) in all three levels of their undergraduate studies. Level one serves as an introduction to both subjects with level two reinforcing and furthering their knowledge-base. The final level, level three, provides further knowledge but also promotes the application of knowledge acquired throughout all three levels of study.

\subsection{Engineering-based curricular in a design context}

The changing expectations of industry have been a consistent motivating factor for the continual development of all curricular within the Loughborough design school. During the previous two academic years both the Mechanics and Electronics syllabus have received a significant redevelopment of their curriculum. Using the changing needs of potential employers and the appointment of new academic staff with relevant expertise, a review was undertaken to understand the current state of engineering-based teaching within the PDT programme and highlight potential improvements in both teaching and learning.

\subsection{Engineering-based curriculum review}

Using a top-down approach, key academic staff developed a list of desirable, industrially relevant engineeringrelated attributes of graduating PDT students. These attributes were then mapped against current learning outcomes of existing engineering-based modules to highlight potential areas of opportunity. Student feedback and consultations through appreciative enquiry techniques were used to determine specific issues and drive discussions. Finally, anecdotal evidence was collated from observations of FYDP outcomes as these are key indicators of transference and the integration of design education learning outcomes. The desirable engineering-related attributes, in no significant order, can be summarised as:

- Strong/broad technical knowledge-base

- Technologically Innovative/creative and pragmatic

- Technologically practised/assured

- Problem defining and solution-focussed 


\section{- Analytical and evaluative}

- Multifaceted

- Collaborative/team orientated

Outcomes of this process revealed that while the levels of Mechanics and Electronics education were appropriate and timely, providing a broad technical knowledge-base, overall student satisfaction was low. It was noted that while PDT students recognised (mostly) the value of the engineering-based education being delivered, their desire for greater levels of applied-learning was high - this was not unexpected. In contrast to the majority of subjects delivered on the PDT programmes, Mechanics and Electronics subjects have operated (mostly) using a traditional lecture-based teaching and learning style, supported with appropriate laboratory activities to reinforce key theoretical aspects. While this is generally an accepted method of delivery to engineering students, design students have a bias towards convergent and assimilation learning styles with obvious characteristics of diverges (Demirbas and Demirkan 2007, Kolb 1984), and therefore benefit from applied learning through application (active experimentation).

Observations of physical product outcomes from the FYDP module demonstrated a general trend of significant engineering-based learning application. However, it also demonstrated weak mechanical design and functionality through the inappropriate use of engineering knowledge, materials and systems. These aspects were echoed in electronic design application, where limited integration of embedded systems and a significant reliance on breadboarding activities for electronic circuits in functional prototypes was recorded. These observations reinforced the appropriateness of the broad technical knowledge-base being delivered but also suggested that practical transference from the engineering-based subjects to design-based subjects was low, further supported students' desires for greater levels of applied-learning.

The findings and observations were related back to the desirable engineering-related attributes. Evidence was found supporting all of their current existence; however, evidence supporting certain attributes was far less prevalent and included:

- Technologically Innovative/creative and pragmatic

- Technologically practised/assured

- Analytical and evaluative

- Collaborative/team orientated

These potential deficiencies highlighted a significant opportunity to improve the current teaching and learning of engineering-based subjects through the introduction of applied learning in a PBL environment. This key aim and the highlighted desirable attributes were used to drive development of the engineering-based pedagogy and resulted in the creation of six new core PDT modules, as demonstrated in Figure 2. 


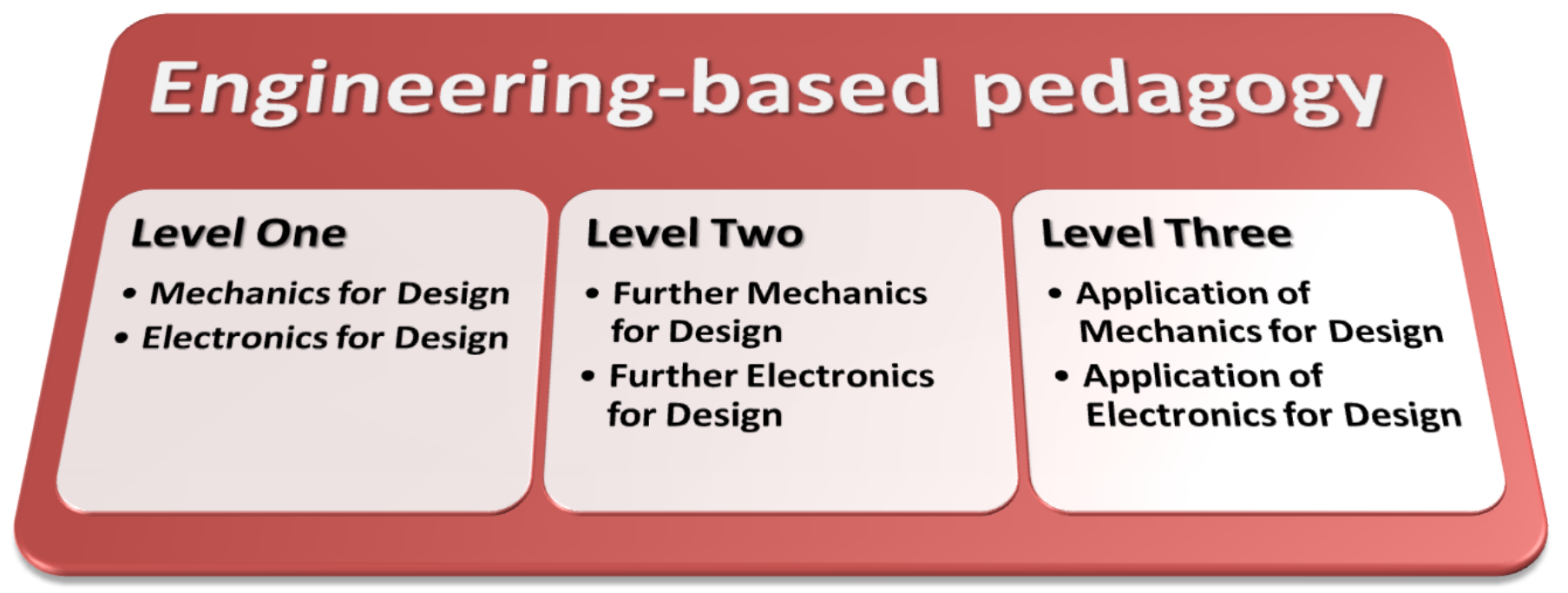

Figure 2: Engineering based modules for the PDT undergraduate programme

The naming of the modules was deliberate to introduce transparency for the broad and deepening educational approach being utilised and also reinforced the purpose of the content directly supporting the design process. Using this remit, all six modules complemented the existing theoretical content with applied aspects through PBL activities to improve the learning experience and promote greater practical transference within the programme.

\subsection{An integrated approach to engineering design education}

The development and implementation of the six new engineering-focused modules fundamentally addressed the findings of the review. However, specifically addressing the observation from FYDP outcomes required further consideration. Complementing existing theoretical engineering content with applied aspects and PBL activities partly addressed these issues. However, providing students with an opportunity to be technologically practiced in a true design context, before undertaking the key FYDP module, was still limited and remained a significant aim.

To achieve this it was decided to further incorporate the design context directly into the engineering-focused modules. Instead of relying almost exclusively on the students' ability to contextualise and transfer engineeringbased knowledge into design practice, this approach helps formalise and reinforce this key learning process. Utilising a design project vehicle where the application of Mechanics and Electronics knowledge was fundamental to its success promotes technological innovation. It also provides students with further opportunities to be technologically practiced. Academic timing for this type of activity was crucial and it was vital that students had the required prerequisite knowledge and practical skills to generate a successful and meaningful outcome. Undertaking a project of this type prematurely in their design education could be detrimental if unsuccessful and therefore negate any of the perceived benefits.

Maintaining the broad and deepening approach, the obvious choice for the delivery of this project was the final year using both the Application of Mechanics for Design (AoM4D) and the Application of Electronics for Design (AoE4D) modules. This allowed both the first and second year engineering-based modules to concentrate on the key aims of introducing and sequentially, furthering/reinforcing students' engineering knowledge-base. The final year module's remit remained the application of this knowledge-base but delivered in a design project context.

Both modules (AOM4D and AoE4D) are delivered in the first semester of the final year only and run concurrently with the first semester activities of the FYDP module. The general schedule of the FYDP module requires research, problem definition, ideation and concept generation in the first semester. The second semester requires prototyping, detailed design, fabrication, evaluation, Design for Manufacture and Assembly (DFMA) activities. While 
design practice is not a linear process as indicated by the activities, providing the students with an engineering design project in semester one enabled a practical rehearsal for the application of engineering-based knowledge in their FYDP project during the semester two activities.

\subsection{Mechanics and Electronics integrated engineering design project}

The core educational aim of the project was to provide the students with a richer, applied learning experience through the design of a physical and functional outcome requiring the significant application of engineering-based knowledge. The benefits of physical models and working prototypes as a vehicle for teaching and learning are well documented (Lemons et al 2010). They are an essential tool in developing judgement via critical evaluation and reflection, and provide students with the opportunity to apply and reinforce their acquired knowledge in a design context (Green and Smrcek 2006).

Providing students with the opportunity to engage in a multidisciplinary, integrated design project also required an integrated approach to the educational delivery of both the Mechanics and Electronics modules. This was achieved by developing a project vehicle that required the same final, physical outcome but enabled the attainment of subject specific objectives that could be academically assessed. Integrating the project work for both engineering modules (AoM4D and AoE4D) enabled a joint project brief to be established that required students to work on parallel activities that would culminate in a singular project outcome. Students were provided subject specific lecture content relevant to project objectives, independently, and supported with dedicated laboratory sessions and weekly tutorials as appropriate. This process allowed an ambitious 'design \& make' project vehicle to be utilised that directly addressed the issues of transference and applied learning.

\subsection{Learning outcomes}

The learning outcomes of the integrated project were developed to reflect the educational aims and opportunities observed from FYDP outcomes. The learning outcomes combined both engineering subjects and reinforced their purpose in the design process through application. These were developed by addressing the fundamental knowledge and understanding outcomes, and then addressing: Intellectual/cognitive skills, Practical/ specific skills and Key/transferable skills. All learning outcomes are summarised in Error! Reference source not found.. 


\begin{tabular}{|c|c|}
\hline \multicolumn{2}{|c|}{ Knowledge and Understanding (KU) } \\
\hline KU 1 & Mechanical design theory and design of machine elements \\
\hline KU 2 & Design issues in programmable and embedded electronic control \\
\hline KU 3 & Design of electrical machines including printed circuit board design and manufacture \\
\hline \multicolumn{2}{|r|}{ Intellectual/Cognitive skills (ICS) } \\
\hline ICS 1 & Apply scientific principles in the modelling and analysis of mechanical and electronic systems \\
\hline ICS 2 & $\begin{array}{l}\text { Apply investigative skills to understand and evaluate performance of devices, } \\
\text { systems and products }\end{array}$ \\
\hline ICS 3 & $\begin{array}{l}\text { Apply mechanical and electronic design competencies to evaluate and generate design criteria related } \\
\text { to the performance and safety of products }\end{array}$ \\
\hline ICS 4 & Apply technical reporting skills on the performance and safety of products \\
\hline \multicolumn{2}{|r|}{ Practical/Specific skills (PSS) } \\
\hline PSS 1 & $\begin{array}{l}\text { Design, prototype, test and evaluate mechanical/electronic control systems to meet a required } \\
\text { product specification }\end{array}$ \\
\hline PSS 2 & $\begin{array}{l}\text { Apply laboratory equipment to produce data and quantify performance parameters for } \\
\text { mechanical/electronic devices, systems and products }\end{array}$ \\
\hline PSS 3 & Apply IT resources for modelling and design of mechanical/electronic systems \\
\hline \multicolumn{2}{|r|}{ Key/Transferable skills (KTS) } \\
\hline KTS 1 & Source, evaluate and manage information from a variety of sources \\
\hline KTS 2 & Use scientific based methods in the solution of technical/physical problems \\
\hline KTS 3 & Use creativity and innovation in problem solving technical/physical problems \\
\hline KTS 4 & $\begin{array}{l}\text { Interact effectively with others, working as a member of a small team to set goals, manage workloads } \\
\text { and meet deadlines }\end{array}$ \\
\hline KTS 5 & Articulate ideas and information comprehensively in visual, oral and written forms \\
\hline KTS 6 & Articulate reasoned arguments through reflection, review and evaluation \\
\hline KTS 7 & Apply skills in information technology in presenting data and reports \\
\hline
\end{tabular}

Table 2: Integrated project learning outcomes

\subsection{The project vehicle: Electro-mechanical can crushing competition}

Finalising a project vehicle and suitable brief for the proposed learning outcomes was a difficult task. Many potential devices/products were proposed and these were judged on their complexity, attainability, likely duration (design and build time) and overall suitability. Fundamentally, the intention was an engineering design project requiring the application of engineering science. It was therefore decided to establish a project brief for an electro-mechanical can crushing device. This project allowed the extensive application of mechanical design while also requiring an intelligent, embedded control system through the significant application of electronic design.

Working in teams of three, each team had a total of 13 weeks to design, fabricate and evaluate an electromechanical drinks can crushing device. The students were asked to develop initial concepts, undertake a full mechanical and electronic analysis, detailed design, fabrication, and a final evaluation of the device and team performance. To ensure that specific learning outcomes were attained, detailed requirements for both the mechanical and electronic aspects of the final crushing device were stipulated as demonstrated in Error! Reference source not found.: 
M1 The device must be powered - not manually operated

M2 The device must be capable of processing both $330 \mathrm{ml}$ and $500 \mathrm{ml}$ aluminium drinks cans

M3 The device must be capable of crushing a drinks can to $20 \%$ of the original uncrushed volume

M4 The device must have the capacity to store a total of five individual cans ready for crushing

M5 The device must be self loading and ejecting of the cans

M6 The device must crush five cans automatically without user intervention

M7 The device must operate via a single push button operation and cease when all stored cans are crushed

\section{Electronic requirements}

E1 The device should be able to provide output on a display on an LCD (Hitachi HD44780 $2 \times 16$ )

E2 This output may display force applied, energy, power, time etc. you may decide on the display criteria

E3 The device will be equipped with calibrated sensor(s) for detecting the force applied and/or other measurands

E4 The electronic control circuit will require input switches, you may decide how the user interacts with the crushing device

E5 The electronic control circuit will be furnished on a PCB not breadboard

E6 The device must incorporate a kill switch/emergency shut off

Table 3: Mechnical and electronic requirments

To promote motivation within the module cohort the project was run as a competition. The aim of the competition was to successfully crush five individual cans in the fastest possible time. While the competition was not a directly assessed component of either module it was a key indicator for the successful attainment of learning outcomes and a significant vehicle for critical reflection and evaluation. It was also used as a vehicle for closure and gave the project greater purpose for the students' and therefore not just another academic exercise. The rules of the competition were stipulated as follows:

- Each teams design must meet all the mechanical and electronic requirements

- Each team will conduct two timed runs: one set of five $330 \mathrm{ml}$ cans, one set of five $500 \mathrm{ml}$ cans

- The recorded times will be combined and an average time calculated

- The fastest recorded average time will be announced as the winner

\subsection{Project assessment}

The project assessments and associated submission dates were developed to support the project brief and introduce a higher-level of project management. Each assessment had a specific aim and represented key aspects of the project that required completion before the next aspect was considered. All submission and timings are demonstrated in Table 2.

\begin{tabular}{c|c|c|c|c|}
$\begin{array}{c}\text { Submission } \\
\text { number }\end{array}$ & $\begin{array}{c}\text { Submission } \\
\text { Mechanics }\end{array}$ & $\begin{array}{c}\text { Submission } \\
\text { Electronic }\end{array}$ & $\begin{array}{c}\text { Submission } \\
\text { Integrated }\end{array}$ & Week \\
\hline 1 & Product Design Specification & Electronic specification & & 3 \\
\hline 2 & Mechanical analysis & Final Electronic PCB & & 6 \\
\hline 3 & & Final design document & & 8 \\
\hline 4 & & & PowerPoint Presentation & 13 \\
\hline 5 & & & Fully functional artefact & 13 \\
\hline 6 & & & Final report & 13 \\
\hline
\end{tabular}

Table 2: key asessment points

\subsection{Project delivery}

The 13 week project was divided into four distinct phases and methods of working. This was undertaken to ensure the aims and learning outcomes were attained and to provide a project management framework for the participating teams. The distinct phases were: 
- Project initialisation - Week one to three

- Project analysis - Weeks four to six

- Project fabrication and testing - Weeks seven to twelve

- Project evaluation - Week thirteen

The specific phases, project activities and student/team deliverables are summarised in Table 3.

\begin{tabular}{|c|c|c|c|}
\hline Project Phases & Wks & Project Activities & Student/Team deliverables \\
\hline \multirow{3}{*}{$\begin{array}{l}\text { Project } \\
\text { initialisation }\end{array}$} & 1 & Initialisation & $\begin{array}{l}\text { Team member selection } \\
\text { Initial planning \& defining of strategies } \\
\text { Quantifying the crushing force required }\end{array}$ \\
\hline & 2 & Ideation & $\begin{array}{l}\text { Individual concept ideas } \\
\text { Product design specification } \\
\text { Electronic requirements \& components }\end{array}$ \\
\hline & 3 & $\begin{array}{l}\text { Concept generation \& } \\
\text { specification }\end{array}$ & $\begin{array}{l}\text { Finalising concepts } \\
\text { Final mechanical specification } \\
\text { Final electronic specification }\end{array}$ \\
\hline \multirow{2}{*}{ Project analysis } & $4-6$ & Mechanical design analysis & $\begin{array}{l}\text { Mechanical analysis of individual concepts } \\
\text { Concept selection based on analysis }\end{array}$ \\
\hline & $4-6$ & PCB generation & $\begin{array}{l}\text { Developing electronic functionality } \\
\text { PCB design }\end{array}$ \\
\hline \multirow{2}{*}{$\begin{array}{l}\text { Project } \\
\text { fabrication \& } \\
\text { testing }\end{array}$} & $7-12$ & $\begin{array}{l}\text { Mechanical prototyping \& } \\
\text { testing }\end{array}$ & $\begin{array}{l}\text { Functional rig development } \\
\text { Fabrication } \\
\text { Final testing }\end{array}$ \\
\hline & $7-12$ & $\begin{array}{l}\text { Electronic prototyping \& } \\
\text { testing }\end{array}$ & $\begin{array}{l}\text { Electronic manufacture } \\
\text { Algorithm design \& programming activities } \\
\text { Final testing }\end{array}$ \\
\hline \multirow{3}{*}{$\begin{array}{l}\text { Project } \\
\text { evaluation }\end{array}$} & 13 & Competition & Demonstration \& competition crushing \\
\hline & 13 & Evaluation \& reflection & Device, performance \& team evaluation \\
\hline & 13 & Final submissions & Final presentation \& group report \\
\hline
\end{tabular}

Table 3: Project phases, project activities and student/team deliverables

Each phase of work required different applications of both mechanical and electrical knowledge and skills, and the attainment of specific project deliverables. Each week, students were provided subject specific lecture content relevant to project objectives, independently, and supported with dedicated laboratory sessions and weekly tutorials as appropriate.

\subsection{Experimental methodology}

To establish the suitability and effectiveness of the proposed teaching and learning activities, the electro-mechanical can crushing project was run for the first time during the initial semester of the 2011/12 academic year. The chosen cohort of 30 PDT students had previously studied Mechanics and Electronics using the older style of engineeringbased curriculum (traditional lecture-based) and this was the first time they had experienced the teaching of engineering-based subjects using a PBL format.

Several data capture techniques were employed to understand the students' experiences and perceptions of the project as follows:

- Project observations

- Post-project questionnaires

- Post-project unstructured interviews and appreciative inquiry 


\subsection{Project observations}

Throughout the project, dedicated weekly tutorials with the individual teams were scheduled. During these weekly tutorials, evaluative feedback was provided to the teams on their direction, progress and likely attainment. The discussions helped steer the projects and reinforce the learning and application of engineering-knowledge in the design process. The weekly tutorials were used to record observations on the delivery of the project, its fundamental appropriateness and the issues experienced by the students.

\subsection{Post-project questionnaire}

To generate statistical data on the suitability and effectiveness of the proposed teaching and learning activities, a two part anonymous questionnaire was developed using a Likert scale. The response scale was assigned numerical values of one $=$ strongly disagree to five $=$ strongly agree in increments of one. This allowed a positive mean of the total response to be calculated and a standard deviation used to show the variance in responses. The first part of the questionnaire directly addressed the desirable engineering-related attributes as identified by academic staff, demonstrated in Table 4.

\begin{tabular}{|c|c|c|c|c|c|}
\hline $\begin{array}{l}\text { Statement or question } \\
\text { Please rate the following statements using an } X \text { in the } \\
\text { corresponding box } \\
\text { Part one: }\end{array}$ & $\begin{array}{l}\text { Strongly } \\
\text { disagree } \\
\text { (1) }\end{array}$ & $\begin{array}{l}\text { Disagree } \\
\text { (2) }\end{array}$ & $\begin{array}{l}\text { Neutral } \\
\text { (3) }\end{array}$ & $\begin{array}{l}\text { Agree } \\
\text { (4) }\end{array}$ & $\begin{array}{l}\text { Strongly } \\
\text { agree } \\
\text { (5) }\end{array}$ \\
\hline \multicolumn{6}{|l|}{$\begin{array}{l}\text { Q1: This project allowed me to develop a strong/broad } \\
\text { technical knowledge base }\end{array}$} \\
\hline \multicolumn{6}{|l|}{$\begin{array}{l}\text { Q2: This project allowed me to be technologically } \\
\text { innovative/creative }\end{array}$} \\
\hline \multicolumn{6}{|l|}{$\begin{array}{l}\text { Q3: This project allowed me to be technologically } \\
\text { practiced/assured }\end{array}$} \\
\hline \multicolumn{6}{|l|}{$\begin{array}{l}\text { Q4: This project allowed me to be problem defining and } \\
\text { solution-focussed }\end{array}$} \\
\hline \multicolumn{6}{|l|}{$\begin{array}{l}\text { Q5: This project allowed me to be analytical and } \\
\text { evaluative }\end{array}$} \\
\hline $\begin{array}{l}\text { Q6: This project allowed me to be more } \\
\text { collaborative/team orientated }\end{array}$ & & & & & \\
\hline
\end{tabular}

Table 4: Post-project questionaire part one - desirable engineering-related attributes

The second part of the questionnaire addressed the students' perception of the project and provided the opportunity to elaborate on every question through personal comments, as demonstrated in Table 5 . The comments were analysed using thematic analysis to further understand the main issues. 


\begin{tabular}{|c|c|c|c|c|c|}
\hline $\begin{array}{l}\text { Statement or question } \\
\text { Please rate the following statements using an } X \text { in the } \\
\text { corresponding box } \\
\text { Part two: }\end{array}$ & $\begin{array}{l}\text { Strongly } \\
\text { disagree } \\
\text { (1) }\end{array}$ & $\begin{array}{l}\text { Disagree } \\
\text { (2) }\end{array}$ & $\begin{array}{l}\text { Neutral } \\
\text { (3) }\end{array}$ & $\begin{array}{l}\text { Agree } \\
\text { (4) }\end{array}$ & $\begin{array}{l}\text { Strongly } \\
\text { agree } \\
\text { (5) }\end{array}$ \\
\hline \multicolumn{6}{|l|}{$\begin{array}{l}\text { Q1: This project allowed me to develop my design for } \\
\text { functionality skills }\end{array}$} \\
\hline \multicolumn{6}{|l|}{ Please comment: } \\
\hline \multirow{2}{*}{\multicolumn{6}{|c|}{$\begin{array}{l}\text { Q2: This project allowed me to develop my } \\
\text { workshop/practical skills } \\
\text { Please comment: }\end{array}$}} \\
\hline & & & & & \\
\hline \multirow{2}{*}{\multicolumn{6}{|c|}{$\begin{array}{l}\text { Q3: This project helped reinforce previous learning of } \\
\text { Mechanics }\end{array}$}} \\
\hline Please comment: & & & & & \\
\hline \multirow{2}{*}{\multicolumn{6}{|c|}{$\begin{array}{l}\text { Q4: This project helped reinforce previous learning of } \\
\text { Electronics } \\
\text { Please comment: }\end{array}$}} \\
\hline & & & & & \\
\hline \multirow{2}{*}{\multicolumn{6}{|c|}{$\begin{array}{l}\text { Q5: Having completed this project, I feel more/better } \\
\text { prepared for my FYDP project } \\
\text { Please comment: }\end{array}$}} \\
\hline & & & & & \\
\hline \multicolumn{6}{|l|}{$\begin{array}{l}\text { Q6: Having completed this project, I feel more/better } \\
\text { prepared for working in the design industry }\end{array}$} \\
\hline \multicolumn{6}{|l|}{ Please comment: } \\
\hline \multicolumn{6}{|l|}{$\begin{array}{l}\text { Q7: Having completed this project, I feel more confident } \\
\text { in Mechanics }\end{array}$} \\
\hline \multicolumn{6}{|l|}{ Please comment: } \\
\hline \multirow{2}{*}{\multicolumn{6}{|c|}{$\begin{array}{l}\text { Q8: Having completed this project, I feel more confident } \\
\text { in Electronics }\end{array}$}} \\
\hline & & & & & \\
\hline
\end{tabular}

Table 5: Post-project questionaire part two - students' perception

\subsection{Post-project unstructured interviews and appreciative inquiry}

The final data capture technique involved the use of unstructured interviews and appreciative inquiry techniques with the students post-project to understand their perception of the project. This allowed the students to raise any issues not captured through the weekly observations and questionnaire. This was complete with individual teams as an activity to increase discussion.

\subsection{Results}

During the first semester of the 2011/12 academic year, 30 PDT students participated in the electro-mechanical can crushing project, resulting in a total of ten student teams. All teams produced a final electro-mechanical can crushing device to varying levels of functionality. The exact level of functionality achieved can be summarised in Table 6 and demonstrates which of the requirements discussed in section 3.2 were delivered. 


\begin{tabular}{|c|c|c|c|c|c|c|c|c|c|c|c|c|c|c|}
\hline \multirow{2}{*}{ Team } & \multicolumn{7}{|c|}{ Mechanical requirements } & \multicolumn{6}{|c|}{ Electronic requirements } & \multirow{2}{*}{$\begin{array}{l}\text { Average cycle } \\
\text { time (seconds) }\end{array}$} \\
\hline & M1 & M2 & M3 & M4 & M5 & M6 & M7 & $E 1$ & E2 & $E 3$ & $E 4$ & $E 5$ & $E 6$ & \\
\hline 1 & $\checkmark$ & $\checkmark$ & $x$ & $\checkmark$ & $\checkmark$ & $r$ & $r$ & $\checkmark$ & $\checkmark$ & $\checkmark$ & $\checkmark$ & $r$ & $\checkmark$ & - \\
\hline 2 & $\checkmark$ & $\checkmark$ & $\checkmark$ & $\checkmark$ & $\checkmark$ & $\checkmark$ & $\checkmark$ & $\checkmark$ & $\checkmark$ & $\checkmark$ & $\checkmark$ & $\checkmark$ & $\checkmark$ & 47 \\
\hline 3 & $\checkmark$ & $\checkmark$ & $x$ & $\checkmark$ & $\checkmark$ & $\checkmark$ & $\checkmark$ & $\checkmark$ & $\checkmark$ & $\checkmark$ & $\checkmark$ & $\checkmark$ & $\checkmark$ & - \\
\hline 4 & $\checkmark$ & $\checkmark$ & $\checkmark$ & $\checkmark$ & $\checkmark$ & $\checkmark$ & $\checkmark$ & $\checkmark$ & $\checkmark$ & $\checkmark$ & $\checkmark$ & $\checkmark$ & $\checkmark$ & 55 \\
\hline 5 & $\checkmark$ & $\checkmark$ & $x$ & $\checkmark$ & $\checkmark$ & $\checkmark$ & $\checkmark$ & $\checkmark$ & $\checkmark$ & $\checkmark$ & $\checkmark$ & $\checkmark$ & $\checkmark$ & - \\
\hline 6 & $\checkmark$ & $\checkmark$ & $\checkmark$ & $\checkmark$ & $r$ & $r$ & $\checkmark$ & $\checkmark$ & $\checkmark$ & $\checkmark$ & $\checkmark$ & $\checkmark$ & $\checkmark$ & 32 \\
\hline 7 & $\checkmark$ & $\checkmark$ & $x$ & $\checkmark$ & $\checkmark$ & $\checkmark$ & $\checkmark$ & $\checkmark$ & $\checkmark$ & $\checkmark$ & $\checkmark$ & $\checkmark$ & $\checkmark$ & - \\
\hline 8 & $\checkmark$ & $\checkmark$ & $x$ & $\checkmark$ & $\checkmark$ & $\checkmark$ & $\checkmark$ & $\checkmark$ & $\checkmark$ & $\checkmark$ & $\checkmark$ & $\checkmark$ & $\checkmark$ & - \\
\hline 9 & $\checkmark$ & $\checkmark$ & $\checkmark$ & $\checkmark$ & $\checkmark$ & $\checkmark$ & $\checkmark$ & $\checkmark$ & $\checkmark$ & $\checkmark$ & $\checkmark$ & $\checkmark$ & $\checkmark$ & 29 \\
\hline 10 & $\checkmark$ & $\checkmark$ & $\checkmark$ & $\checkmark$ & $\checkmark$ & $\checkmark$ & $\checkmark$ & $\checkmark$ & $\checkmark$ & $\checkmark$ & $\checkmark$ & $\checkmark$ & $\checkmark$ & 38 \\
\hline
\end{tabular}

Table 6: Mechanical and electronic functional requirement matrix

Table 6 demonstrates that only five teams were successful in producing a fully-functional crushing device capable of recording an average cycle time for both sizes of can specified. While this figure is somewhat low, the design process utilised and learning outcomes attained by the students was considered more significant than the actual functional outcome. The delivery of a fully-functional crushing device was an indicator for the successful application of engineering knowledge in a design context. However, the projects main educational aim was application driven, providing an opportunities to be technologically practiced and a vehicle for reflection and evaluation. Examples of the crushing devices produced are demonstrated in Figure 3.
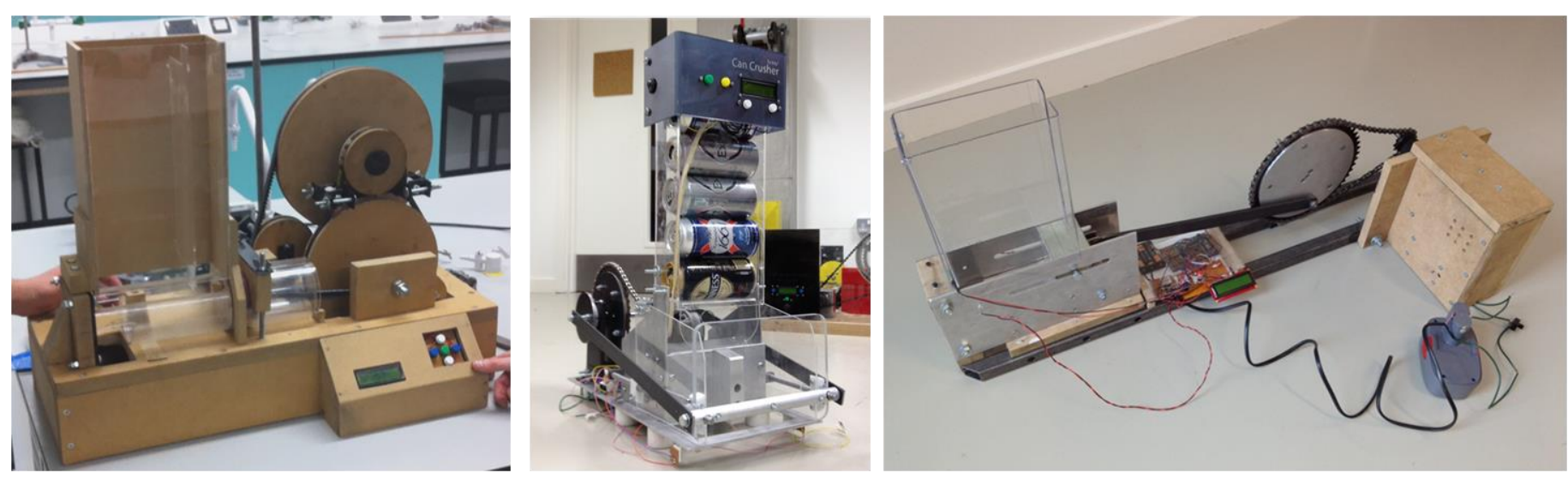

Figure 3: Example student crushing devices

\subsection{Project observations results}

Throughout the project, dedicated weekly tutorials with the individual teams were scheduled and used to record observations on the delivery of the project, its fundamental appropriateness and the issues experienced by the students. The key outcomes of this process are discussed for each phase of the project.

\subsubsection{Project initialisation - Week one to three}

The first three weeks of the project were well received and the students demonstrated a keen motivation for the project, relishing the opportunity to engage in the design process. All teams used a variety of web resources to collate existing solutions and investigate their potential for improvement and inclusion in their designs. Each team also developed a vast amount of potential solutions and concepts to meet the fundamental requirements of the project. Parallel activities for quantifying the crushing force required was also viewed as a fun activity and students happily engaged in scientific based investigations to determine this key data.

Sequential activities for developing a team specific Product Design Specification (PDS) were less well received and resulted in some teams questioning its value. However, all teams were reminded of the design process and the need 
to develop a list of key criteria to allow the generation of suitable concept designs. They were also reminded of the requirement to evaluate their design decisions and outcomes, and the value of the PDS as a vehicle for this activity. This evaluative and instructional feedback motivated the teams and resulted in the production of detailed and suitable PDS documents. The final activity of the initial phase involved concept generation and the direct application of the design process. All students readily engaged in this activity using a variety of design techniques including sketching, sketch modelling and CAD work. A significant proportion of the cohort utilised virtual prototyping techniques to produce animated CAD models to verify their decisions and demonstrate their intended functionality. The appropriate use of CAD also resulted in the production of high-quality rendered images of their final concept design. The specific learning outcomes included within this phase of the project are summarised in Table 7.

\begin{tabular}{|c|c|}
\hline Activity & Learning outcomes \\
\hline Project initialisation & ICS 2, PSS 2, KTS 1, KTS 2, KTS 3, KTS 4, KTS 5 \\
\hline Ideation & $K U 1, K U 2, K U$ 3, ICS 2, ICS 3, PSS 1, PSS 3, KTS 1, KTS 2, KTS 3, KTS 4, KTS 5 \\
\hline $\begin{array}{l}\text { Concept generation \& } \\
\text { specification }\end{array}$ & $\begin{array}{l}K U 1, K U 2, K U \text { 3, ICS 1, ICS 3, ICS 4, PSS 1, PSS 3, KTS 1, KTS 2, KTS 3, KTS 4, KTS 5, } \\
K T S 7\end{array}$ \\
\hline
\end{tabular}

Table 7: Learning outcomes involved in project initialisation

\subsubsection{Project analysis - Weeks four to six}

The second phase of the project was the vehicle for the majority of engineering-based knowledge and learning application. Here the students applied their previously acquired engineering-based knowledge to the design process. In contrast to the previous three weeks of project, this period involved a separation of mechanical and electronicbased activities as follows.

\section{- Mechanical design analysis}

Working both collaboratively and individually, each team member was responsible for the production of a full mechanical analysis of their concept design. This activity required the student to utilise a range of mechanical science topics to calculate expected loads, resulting stresses and appropriate material dimensions to ensure their final detailed design was mechanically viable.

Observations from the weekly tutorials revealed that students were again motivated by this activity but also found the process difficult. Reoccurring comments revealed that they understood (mostly) the theory of the mechanical science topics being utilised but struggled to actually apply these concepts into the design process for the generation of a physical fully-functional artifact. Here the students were removed from the comfort-zone of working theoretically using typical calculation-based questions or laboratory activities with model answers and results. Students experienced uncertainty and expressed concerns that they were overwhelmed by the potential enormity of the task and failed to recognise where they should start or how to correctly apply their engineering knowledge.

Evaluative feedback was again used to steer their analysis and demonstrate the appropriate use of mechanical science. Using individual consultations, students were directed to exam aspects of the concept and relate these directly to standard cases for static and dynamic loading conditions. This process helped remove some of their uncertainty and reengaged them in this key learning activity. Eventually students began to fully recognise the importance of the prior theoretical learning and understood how this was directly relevant to the design process. This was an important outcome of the project and allowed students to apply their prior learning in a true design context.

\section{- PCB generation}

Mirroring the concerns and difficulties experienced in the mechanical analysis, teams also struggled with the application of electronic-based knowledge and learning in the design of their embedded, intelligent control system. Working collaboratively, each team was responsible for developing their electronic functionality and specifying key measurands. Again students commented that they were overwhelmed by the task, removed from their comfortzone and experienced uncertainty through the lack of model answers and results. Using individual team tutorials, the 
students were directed to exam their specified electronic requirements and relate these to prior learning activities for potential solutions. Segregating tasks allowed the teams to sequentially address specific requirements and enabled the final development of the integrated functionality. Teams began to engage in flowcharting their program operation and description of their user interface. Parallel breadboard activities were also used to test their circuit operations before developing schematics for a final PCB design. This was another important outcome of the project and allowed students to apply their prior learning in a true design context.

The specific learning outcomes included within this phase of the project are summarised in Table 8.

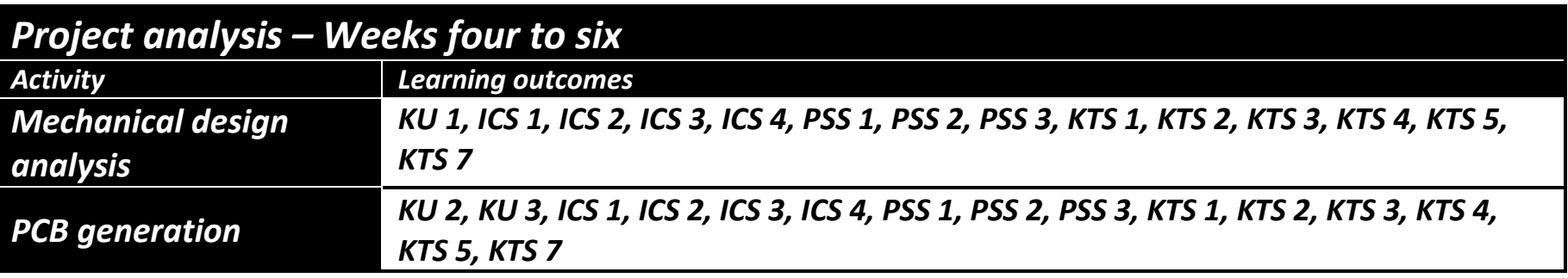

Table 8: Learning outcomes involved in project analysis

\subsubsection{Project fabrication and testing - Weeks seven to twelve}

The third phase of the project involved the fabrication and realisation of their crushing devices. Here the teams were responsible for translating their applied theoretical work into fully-functional, physical artifacts. Feedback from the students again showed that they were highly motivated by this activity and relished the opportunity to apply their theoretical work to a physical outcome. However, teams quickly began experiencing difficulties in the translation from theoretical to actual through a lack of practical fabrication or workshop experience/skills. Team consultations revealed that practical fabrication skills developed from prototyping activities in previous design projects did exist. However, these were limited and this was (potentially) the first instance where students were required to actually produce a fully-functional device. All previous prototyping activities had concentrated on form and finish only rather than true functionality through mechanical design.

This step-change in emphasis required the students to be more meticulous with their planning and deliberate with their execution, resulting in a much longer fabrication period than initially anticipated. Weekly team tutorials were used to direct this process and provide practical advice on the fabrication of machine elements. As a consequence, a significant number of teams re-examined their chosen design and re-engaged in CAD modelling to finalise their designs completely. The second generation CAD models were far more detailed and included additional manufacturing details previously ignored. The CAD models were used to generate technical drawings of required components that were then fabricated to the required tolerances.

In parallel, teams were fabricating their final $\mathrm{PCB}$, generating their final program code and considering the integration of their embedded control system into the crushing device. This was another significant task and again feedback revealed considerable difficulties. Students commented that while they were confident producing isolated functionality they were sceptical of successfully integrating both mechanical and electronic elements. Weekly team tutorials were again used to direct this process and provide practical advice to deliver this key requirement.

The physical prototyping aspects of this project were a crucial learning activity and provided the students with a vehicle for the evaluation of design decisions and an opportunity to be technologically practised. Students were able to reflect more easily on the decision they took and directly evaluate their outcomes. Feedback from the students indicated that this was an extremely beneficial activity and provided practical experience that could be applied in related areas of their FYDP. The specific learning outcomes included within this phase of the project are summarised in Table 9. 


\section{Project fabrication \& testing - Weeks seven to twelve}

Activity

Mechanical prototyping,

fabrication \& testing

Electronic prototyping,

manufacture \& testing
Learning outcomes

KU 1, ICS 1, ICS 2, PSS 1, PSS 2, PSS 3, KTS 2, KTS 3, KTS 4, KTS 5, KTS 6

KU 2, KU 3, ICS 1, ICS 2, PSS 1, PSS 2, PSS 3, KTS 2, KTS 3, KTS 4, KTS 5, KTS 6

Table 9: Learning outcomes involved in project fabrication and testing

\subsubsection{Project evaluation and final submission - Week thirteen}

The final phase of the project involved the competition, evaluation and final submissions. The competition was not a directly assessed component but provided the teams with a key indication for the success of their design decisions and a vehicle for reflection and evaluation. It also provided students with the opportunity to examine and evaluate alternative design decision made by competitive teams and further increase their technical knowledge-base.

The reflection and evaluation was a crucial aspect of the project as it allowed the students to reinforce their learning and translate best practice to subsequent design projects (FYDP) via technological experience. The reflection and evaluation was recorded in two assessed components, the final team presentation and report. The presentations allowed the teams to summaries their project and evaluate the key aspects to the entire cohort - this provided all teams with the opportunity to assimilate potential issues and elements of best practice. The written evaluation was delivered in greater detail and provided the teams with a further opportunity to reflect more deeply on their design decisions and construct these into reasoned arguments for potential improvements of further/related work. All students enthusiastically engaged in this process and were surprisingly honest in their evaluation. Most students recognised their limitations and revealed a genuine lack of understanding when required to apply their previously acquired knowledge-base in a practical situation. All students commented on the high value of the exercise and opportunity to apply their knowledge-base in a true design context.

The specific learning outcomes included within this phase of the project are summarised in Table 10.

\begin{tabular}{|c|c|}
\hline Activity & Learning outcomes \\
\hline Competition & $K U 1, K U 2, K U 3, K T S 4, K T S 6$ \\
\hline Evaluation and reflection & $K U 1, K \cup 2, K U$ 3, ICS 4, PSS 3, KTS 4, KTS 5, KTS 6, KTS 7 \\
\hline Final submissions & $K U 1, K U 2, K U$ 3, ICS 4, PSS 3, KTS 4, KTS 5, KTS 6, KTS 7 \\
\hline
\end{tabular}

Table 10: Learning outcomes involved in project evaluation and final submission

\subsection{Post-project questionnaire results}

From the module cohort of 30 PDT students, 22 completed questionnaires were received resulting in a total response of $73.3 \%$.

5.2.1 Post-project questionnaire results part one

The results from the first part of the questionnaire are demonstrated in Table 11.

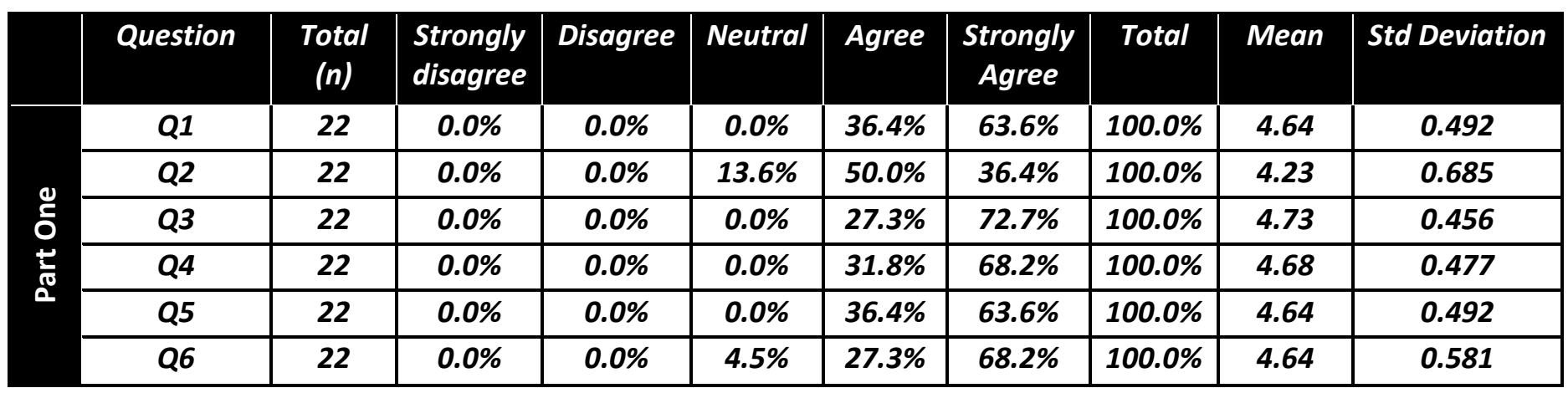

Table 11: Post-project questionaire part one results 
The results indicated in Table 11 establish the student responses to the opportunities for demonstrating the desirable engineering-related attributes within the project. All but two attributes received a totally positive response with neutral responses recorded for Q2, opportunities to be technologically innovative/creative and Q6, more collaborative/team orientated. The mean values for all the attributes indicate, that in general, all students agreed that the project allowed them to demonstrate the desirable engineering-related attributes within the project.

The results of the questionnaire are presented graphically in Figure 4.

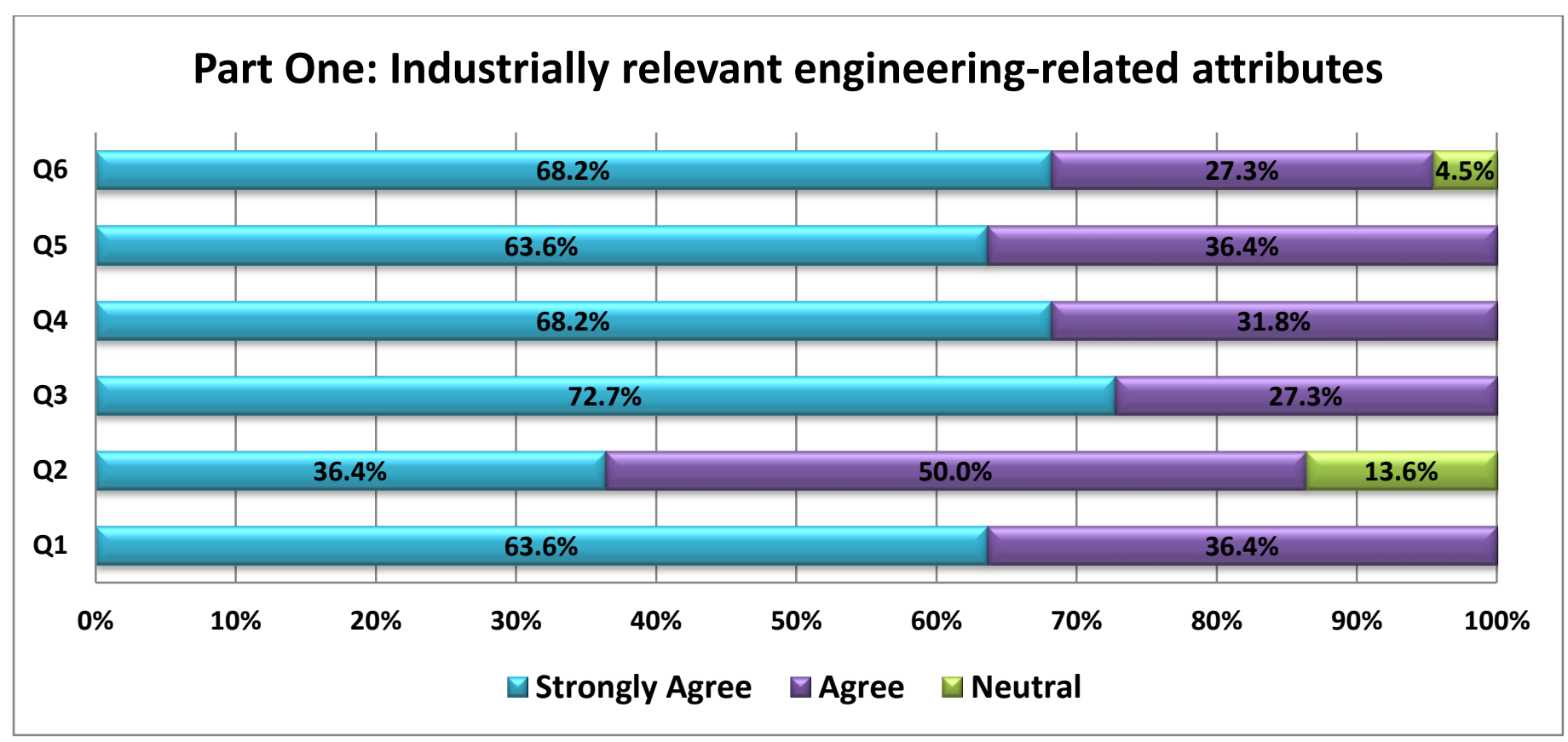

Figure 4: Post-project questionaire part one results

\subsubsection{Post-project questionnaire results part two}

The results of the second part of the questionnaire are demonstrated in Table 12.

\begin{tabular}{c|c|c|c|c|c|c|c|c|c|c|}
\hline Question & $\begin{array}{c}\text { Total } \\
(n)\end{array}$ & $\begin{array}{c}\text { Strongly } \\
\text { disagree }\end{array}$ & Disagree & Neutral & Agree & $\begin{array}{c}\text { Strongly } \\
\text { Agree }\end{array}$ & Total & Mean & Std Deviation \\
\hline Q1 & 22 & $0.0 \%$ & $0.0 \%$ & $4.5 \%$ & $45.5 \%$ & $50.0 \%$ & $100.0 \%$ & 4.45 & 0.596 \\
\hline$Q 2$ & 22 & $0.0 \%$ & $0.0 \%$ & $4.5 \%$ & $40.9 \%$ & $54.5 \%$ & $100.0 \%$ & 4.50 & 0.598 \\
\hline$Q 3$ & 22 & $0.0 \%$ & $4.5 \%$ & $4.5 \%$ & $27.3 \%$ & $63.6 \%$ & $100.0 \%$ & 4.50 & 0.802 \\
\hline$Q 4$ & 22 & $0.0 \%$ & $18.2 \%$ & $27.3 \%$ & $40.9 \%$ & $13.6 \%$ & $100.0 \%$ & 3.50 & 0.964 \\
\hline$Q 5$ & 22 & $0.0 \%$ & $4.5 \%$ & $22.7 \%$ & $31.8 \%$ & $40.9 \%$ & $100.0 \%$ & 4.09 & 0.921 \\
\hline$Q 6$ & 22 & $0.0 \%$ & $0.0 \%$ & $18.2 \%$ & $63.6 \%$ & $18.2 \%$ & $100.0 \%$ & 4.00 & 0.617 \\
\hline$Q 7$ & 22 & $0.0 \%$ & $0.0 \%$ & $0.0 \%$ & $36.4 \%$ & $63.6 \%$ & $100.0 \%$ & 4.64 & 0.492 \\
\hline$Q 8$ & 22 & $0.0 \%$ & $22.7 \%$ & $13.6 \%$ & $59.1 \%$ & $4.5 \%$ & $100.0 \%$ & 3.45 & 0.912 \\
\hline
\end{tabular}

Table 12: Post-project questionaire part two results

The results indicated in Table 12 show greater variance and exhibit large standard deviations than those documented for the first part of the questionnaire. The student comments for each question were collated and themes developed for each question as follows:

Q1: This project allowed me to develop my design for functionality skills

The response to this question was largely positive with only $4.5 \%$ recording a neutral response. The themes drawn from the personal comments can be summarised as:

- Emphasis: Students commented on the nature of the project and related how this was the first opportunity to concentrate and deliver actual functionality within a design project. 
- Physicality: Students commented on the importance of producing a functional artifact and how this provided a reference object to evaluate their design decisions.

- Clarity: Students commented on the clarity of the design project and the benefits of the functional requirements enabling them to concentrate on the important aspects.

\section{Q2: This project allowed me to develop my workshop/practical skills}

The response to this question was again largely positive with only $4.5 \%$ of the responses being neutral. The themes drawn from the personal comments can be summarised as:

- Avoidance: Students who provided a neutral response commented that due to the group activity, the workshop aspects of the project could be avoided in favour of the design and electronic aspects.

- Familiarisation/consolidation: Conversely, positive responses included comments relating to their year out in industry and the project enabled them to re-familiarise with the workshop facilities.

- Expectation: Positive responses coincided with comments relating to expectation management and the apparent difference between design intention and fabrication reality.

\section{Q3: This project helped reinforce previous learning of Mechanics}

The responses to this question were mixed with $4.5 \%$ disagreeing and $4.5 \%$ of the responses being neutral. The mean of all the responses was 4.50 (the second highest in the dataset) but received a standard deviation of 0.802 . The themes drawn from the personal comments can be summarised as:

- Knowledge gap: Students who disagreed or provided a neutral response commented that while they appreciated the application of mechanics within the project, the previous learning using the lecture-based curriculum was not directly beneficial and require extensive relearning.

- Familiarisation/consolidation: Conversely, positive responses included comments relating to their year out in industry and the project enabled them to re-familiarise with the subject matter and consolidate previous learning.

Recurring themes in the context of previous learning of Mechanics included physicality.

\section{Q4: This project helped reinforce previous learning of Electronics}

The responses to this question were again mixed and received the second lowest overall mean (3.50) and highest stand deviation of 0.964 . The themes drawn from the personal comments can be summarised as:

- Avoidance: Students who disagreed or provided a neutral response commented that due to the group activity, the electronic aspects of the project could be avoided in favour of the practical and workshop aspects.

- Suitability: Students who disagreed or provided a neutral response questioned the apparent suitability of the electronics work and suggested this was unrelated to the design industry.

Recurring themes in the context of previous learning of Electronics included: knowledge gap, familiarisation/consolidation and physicality.

\section{Q5: Having completed this project, I feel more/better prepared for my FYDP project}

The responses to this question were again mixed but received overall mean of 4.09 and the second highest stand deviation of 0.921 . Interestingly, respondents that disagreed or gave neutral responses did not comment and therefore their reasoning is unknown. The themes drawn from the personal comments can be summarised as:

- Rehearsal/transference: Positive responses corresponded with comments relating to the opportunity to rehearse the engineering-design process prior to the FYDP module and the ability transfer best practice through experience.

- Expectation: Positive responses coincided with comments relating to expectation management and the apparent difference between design intention and fabrication reality. 
- Project management: Students commented on the greater appreciation of project management issues and how this will inform their planning of major project work.

\section{Q6: Having completed this project, I feel more/better prepared for working in the design industry}

The responses to this question were again positive with only $18.2 \%$ of the responses being neutral. The themes drawn from the personal comments can be summarised as:

- Uncertainty: Neutral comments corresponded with comments expressing uncertainty in the design industry and how the work completed in the project related to that of current product design practice.

- Integration: Conversely, positive comments expressed the suitability of the project work in relation to the integration of both mechanical and electronic control systems and how this was indicative for the majority of product design work.

- Team working: Students commented on the greater appreciation of team working issues and how this will be valuable when working in the design industry.

Recurring themes in the context of working in the design industry included: project management and rehearsal/transference.

\section{Q7: Having completed this project, I feel more confident in Mechanics}

The responses to this question were all positive with a mean of 4.64 and standard deviation of 0.492 . The themes drawn from the personal comments can be summarised as:

- Application: Students commented on the greater appreciation of applying mechanical theory to real-world objects and the design process.

- Clarity: Students also commented on the level of understanding achieved through the application of mechanical theory to real-world objects and the design process.

Recurring themes in the context of confidence in Mechanics included: familiarisation/consolidation and rehearsal/transference.

\section{Q8: Having completed this project, I feel more confident in Electronics}

The responses to this question were again mixed and received the lowest overall mean of 3.45 and stand deviation of 0.912 . The themes drawn from the personal comments can be summarised as:

- Knowledge gap: Students who disagreed or provided a neutral response commented that while they appreciated the application of electronics within the project, the previous learning using the lecture-based curriculum was not directly beneficial and require extensive relearning.

- Support/application: Students who disagreed or provided a neutral response also suggested that academic support for the project was insufficient and more was required for the application of theoretical knowledge.

- Application: Conversely, positive comments expressed the greater appreciation of applying electronic theory to real-world objects and the design process.

- Clarity: Students also commented on the level of understanding achieved through the application of electronic theory to real-world objects and the design process.

Recurring themes in the context of confidence in Electronics included: familiarisation/consolidation, rehearsal/transference and avoidance.

The results of the questionnaire are presented graphically in Figure 5. 


\section{Part Two: Students' experience}

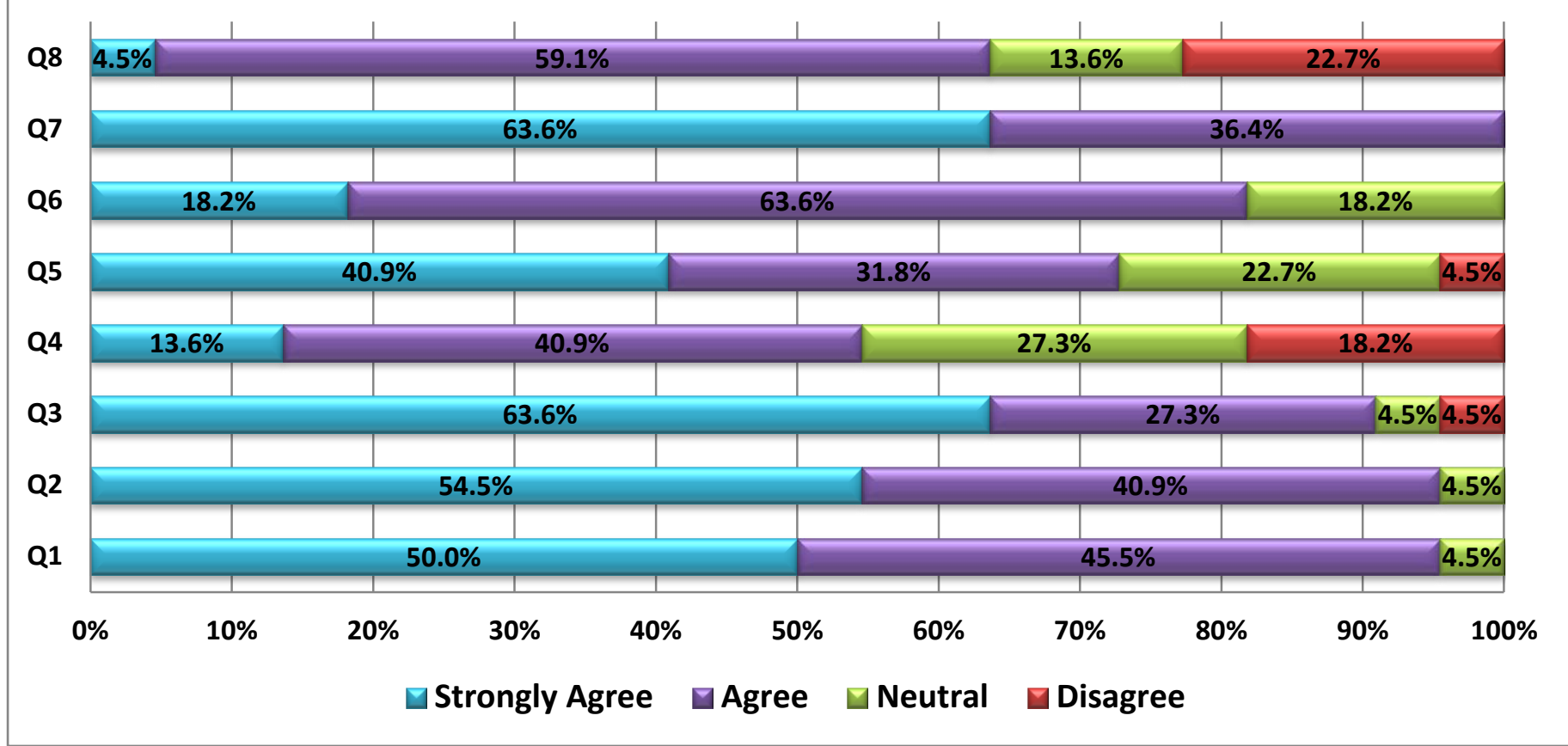

Figure 5: Post-project questionaire part two results

\subsection{Post-project unstructured interviews and appreciative inquiry discussion}

Unstructured interviews and appreciative inquiry techniques where used with students post-module to understand their perception of the project and revealed some interesting insights. Students really appreciated the opportunity to apply both Mechanics and Electronics-based learning in a single design project but found the project very technically and time demanding. Reoccurring comments included:

- "I've learnt more in this project (about Mechanics and electronics) than the previous two years of study"

- "Applying Mechanics and Electronics to a real-world design problem really helped me better understand the subjects"

- "Actually building something that works was a real challenge but will really help my FYDP project"

- "Why don't we have more projects like this"

- "The project is too demanding and the does not reflect the credit weighting"

- "Too many assessment points"

While the comments received are subjective and can only be treated as anecdotal evidence at best, they do suggest the project provides intrinsic educational value and a suitable approach for combining the design context directly into engineering-based pedagogy.

\subsection{Final discussion}

The integrated project presented was developed to address the changing requirements of product design practice, increase the attainment of industrially desirable attributes of graduates and address the educational opportunities discovered from a review of engineering-based teaching and learning.

The targeted cohort of 30 final year PDT students used within the study had previously experienced a traditional lecture-based approach to the teaching and learning of both Mechanics and Electronics. This provided a value comparison for the teaching of engineering-based subjects using a PBL format.

The observations of project implementation and delivery highlighted that all of the intended outcomes have been numerously addressed in all four phases of the project. The project provided the students with an applied learning 
experience using a PBL environment and incorporated the design context directly into engineering-based pedagogy, addressing the issues of transference.

The results of the post-project questionnaire and analysis established that the students, in general, were positive that the project allowed them the opportunity to gain valuable experience of demonstrating the desirable engineering-related attributes. The second part of the post-project questionnaire and analysis also established the project's capability of increasing desirable practical skills, reinforcing previous learning and preparing them for FYDP and ultimately the demands of industry. While this indicates a potential success, the exact relevancy of these learning outcomes, skills and attributes to the changing requirements of product design practice is not yet fully understood and further time is required to ascertain its true impact.

\subsection{Conclusions}

The teaching of engineering design to engineering students is a well-documented subject. However, the teaching of engineering design to design students is much less documented. The approached developed here aimed to provide design students with a richer learning experience by delivering integrated engineering-based learning within the design context and address the issues of low transference observed at the Loughborough Design School.

Traditional design pedagogy is delivered almost exclusively through applied learning using PBL activities. In contrast engineering-based subjects are often delivered to design students using are more traditional lecture-based approach. A review of this approach indicated a potential consequence for low transference to the design process.

This study was restricted to a single University and therefore wider conclusion regarding design education cannot be made with total authority. However, the result indicate that supplementing the traditional lecture-based approach with an integrated 'design and make' project vehicle, requiring the extensive application of engineering-base knowledge, allowed the key cognitive learning process of transference to be formally addressed. This provided Product Design students with a richer and more beneficial learning experience and more adequately prepared them for the changing expectations of industry and product design employment. 


\subsection{References}

- ABET. (2012), Criteria for accrediting engineering programmes (ABET), http://www.abet.org/ (accessed December 2012)

- Atman, C., \& Turns, J. (2001). Studying engineering design learning: Four verbal protocol studies. In C. Eastman, W. McCracken, \& W. Newstetter (Eds.), Design knowing and learning: Cognition in design education (pp. 37-60). Oxford, UK: Elsevier Science.

- Atman, C., Cardella, M., Turns, J., \& Adams, R. (2005). Comparing freshman and senior engineering design processes: An in-depth follow up study. Design Studies, 26(4), pp.325-357.

- Atman, C., Chimka, J., Bursic, K., \& Nachtmann, H. (1999). A comparison of freshman and senior engineering design processes. Design Studies, 20(2), pp.131-152.

- Bransford, J.D., Brown, A.L., \& Cocking, R.R.(1999) eds., How People Learn: Brain, Mind, Experience and School, Washington, D.C.: National Academy Press.

- Bursic, K., \& Atman, C. (1997). Information gathering: a critical step for quality in the design process. Quality Management Journal, 4(4), pp.60-75.

- Christiaans, H., \& Dorst, K. (1992). Cognitive models in industrial design engineering: a protocol study. Design Theory and Methodology, 42, pp.131-137.

- Cross, N. (2001). Design cognition: Results from protocol and other empirical studies of design activity. In C. Eastman, M. McCracken, \& W. Newstetter (Eds.), Design knowing and learning (pp. 79e103). New York: Elsevier.

- Cross, N.(2000). Engineering Design Methods - Strategies for Product Design, (3rd edn), 2000 (Wiley).

- de Vere, I., Melles, G., \& Kapoor, A. (2010). Product design engineering - a global education trend in multidisciplinary training for creative product design. European Journal of Engineering Education, 35(1), pp.33-43.

- Demirbas, O, O. \& Demirkan, H. (2007) Learning styles of design students and the relationship of academic performance and gender in design education, Learning and Instruction 17(3), p345-359

- Dominick, P.G., Demel, J.T., Lawbaugh,W.M., Freuler, R.J., Kinzel, G.L. and Fromm, E.(2001). Tools and Tactics of Design, 2001 (Wiley).

- Dym, C.L. and Little, P. (2000). Engineering Design -A Project-based Introduction, 2000 (Wiley).

- Ennis, C., \& Gyeszly, S. (1991). Protocol analysis of the engineering systems design process. Research in Engineering Design, 3(1), pp.15-22.

- Grasso, D., \& Martinelli, D. (2007). Holistic engineering. Chronicle of Higher Education, 53, B8-B9.

- Green, G., \& Smrcek, L. (2006). On the developing role of physical models in engineering design education. European Journal of Engineering Education, 31(2), pp.191-200.

- Hyman, B. (1998). Fundamentals of Engineering Design, 1998 (Prentice Hall: Englewood Cliffs, NJ). Introduction to engineering design (GE107), http://www.eeng.may.ie/jringwood/undrgrad/lectpage.htm.

- Kolb, D. A. (1984). Experiential learning: Experience as the source of learning and development. New Jersey: Prentice-Hall.

- Kruger, C., \& Cross, N. (2006). Solution driven versus problem driven design: strategies and outcomes. Design Studies, 27(5), pp.527-548.

- Lemons, G., Carberry, A., Swan, C., Jarvin, L., \& Rogers, C. (2010). The benefits of model building in teaching engineering design. Design Studies, 31(3), pp. 288-309.

- Morris, R., Childs, P., \& Hamilton, T. (2007). Sustainability by design: a reflection on the suitability of pedagogic practice in design and engineering courses in the teaching of sustainable design. European Journal of Engineering Education, 32(2), pp.135-142.

- Pahl, G. (1999). Resume of 12 years interdisciplinary empirical studies of engineering design in Germany. Design Studies, 20(5), pp.481-494.

- Pugh, S. (1991). Total Design - Integrated Methods for Successful Product Engineering, 1991 (Addison-Wesley).

- Radcliffe, D., \& Lee, T. (1989). Design methods used by undergraduate engineering Students. Design Studies, 10(4), pp.199-207.

- Salt, J.E. and Rothery, R. (2002). Design for Electrical and Computer Engineers, 2002 (Wiley). 
- Savin-Baden M. and Major C.H. (2004) Foundations of Problem Based Learning, 2004 (McGraw-Hill Education, Berkshire, GBR)

- Slack, L., (2006). What is product design? Mies, Switzerland: RotoVision.

- Southee, D. (2005). Single point design in the context of higher education. Crossing Design Boundaries: Proceedings of the 3rd Engineering \& Product Design Education International Conference, 15-16 September 2005, Edinburgh.

- Stauffer, L., \& Ullman, D. (1988). A comparison of the results of empirical studies into the mechanical design process. Design Studies, 9(2), pp.107-114.

- Voland, G. (1999). Engineering by Design, 1999 (Addison-Wesley). 